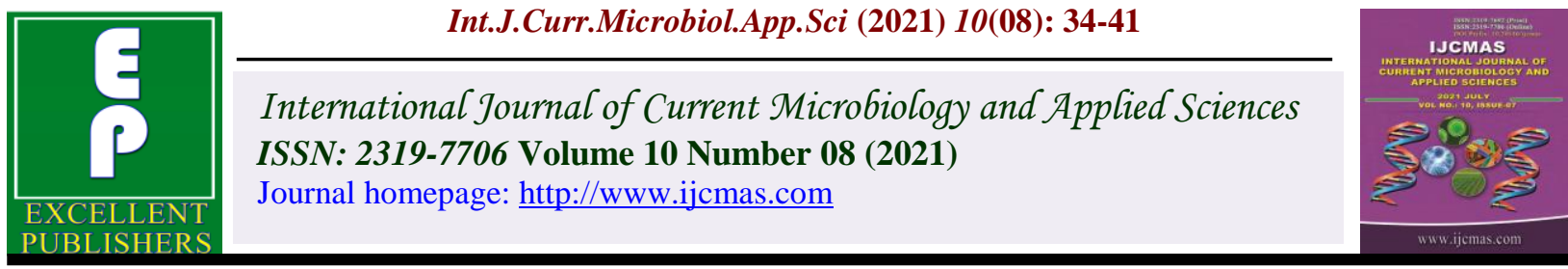

\title{
Detrimental Effects of Acrylamide Induced Cardiotoxicity and its Amelioration in Adult Male Wistar Rats
}

\author{
Pratishtha Sharma ${ }^{1}$, Sharad K. Yadav ${ }^{2}$, Amit Kumar ${ }^{3}$, Vinod K. Singh ${ }^{4}$, \\ Renu Singh ${ }^{5}$, Vikas Pathak ${ }^{6}$ and Dilip Kumar Swain ${ }^{7}$
}

${ }^{1}$ Department of Biotechnology, ${ }^{2}$ Department of Microbiology and Immunology

${ }^{3}$ Department of Immunology and Defense Mechanism, College of Biotechnology, SVPUAT, Meerut-250110, Uttar Pradesh, India

${ }^{4}$ Department of Veterinary Pathology, ${ }^{5}$ Department of Livestock and product management,

${ }^{6}$ Department of Veterinary Physiology, ${ }^{7}$ Department of Veterinary Science and Animal

Husbandry, U.P. Pandit Deendayal Upadhayaya Pashu Chikitsa Vigyan Vishwavidyalaya

Evam Go Anusandhan Sansthan, Mathura - 281001, Uttar Pradesh, India

*Corresponding author

\begin{tabular}{l} 
K e y w o r d s \\
$\begin{array}{l}\text { Acrylamide, } \\
\text { antioxidant, } \\
\text { cardiotoxicity, } \\
\text { heart, oxidative } \\
\text { stress }\end{array}$ \\
\hline Article Info \\
$\begin{array}{l}\text { Accepted: } \\
\text { 10 July } 2021 \\
\text { Available Online: } \\
\text { 10 August } 2021\end{array}$ \\
\hline
\end{tabular}

\section{Keywords}

Acrylamide antioxidant, cardiotoxicity, heart, oxidative Article Info

Accepted: Available Online: 10 August 202
Present study was designed to evaluate and investigate the cadiotoxicity induced through oral feeding of acrylamide (ACR) and its amelioration strategies using different antioxidants in Wistar rat model. A total number of 32 adult male Wistar rats were divided into eight groups (G1-G8) G1, (Basal Diet only), G2 ( $\alpha$-tocopherol+basal diet), G3 (GSH), G4 (Corn oil), G5 (ACR), G6 (ACR+ $\alpha$-tocopherol G7 (ACR + GSH) and G8 (ACR + $\alpha$ tocopherol+ GSH). ACR, $\alpha$-tocopherol and GSH were orally administered to rats @ 30 $\mathrm{mg} / \mathrm{KgBW}, 5 \mathrm{IU} / \mathrm{KgBW}$ and $2 \mathrm{mg} / \mathrm{KgBW}$, respectively for 45 days. The study revealed significant reduction in body and heart weights in ACR fed rats (G5) compared to control rats (G1-G4) whereas, the weight were significantly restored in (G6-8). Heart tissues were collected after $45^{\text {th }}$ day for the assessment of morphological, biochemical, histopathological and oxidative stress parameters. ACR intoxication resulted in oxidative stress as evident from higher levels of MDA and lower activities of antioxidative enzymes SOD, GSH, GST and CAT in rats (G5) compared to (G1-4). These parameters showed significant $(\mathrm{P}<0.05)$ restoration in $(\mathrm{G6})$. Serum biochemical parameters were restored in G6 and G7 compared to G5.Histopathologically, the heart tissues revealed severe degeneration, necrosis and separation of cardiac muscle fibers with extravassation of RBCs in (G5) while it was restored and marked improvement was visible in ameliorating groups (G6-G8) in comparison to (G5). With the end of the study in conclusion it was evident that $\alpha$-tocopherol and GSH played substantial role in maintaining the balance between oxidant and antioxidant mechanisms and in specific, $\alpha$-tocopherol conferred better protection from ACR induced cardiotoxicity. 


\section{Introduction}

Acrylamide or 2-propenamide is a chemical compound, with chemical formula $\mathrm{CH} 2=\mathrm{CH}-$ $\mathrm{CO}-\mathrm{NH} 2$, is a colorless, non-volatile crystalline solid, soluble in water and has a molecular weight of $71.08 \mathrm{kDa}$ that can be produced at high levels in high-carbohydrate heat treated foods (Ashoor et al., 1984; Eriksoon 2005). The risks of ACR to health and its toxic properties (neurotoxicity, genotoxicity, carcinogenicity and reproductive toxicity) were demonstrated by the Scientific Committee on Toxicity, Ecotoxicity and the Environment in 2001 (Keramat et al., 2011; Carere, 2006). Potato and bakery products account for around $50 \%$ and $20 \%$ of human exposure to ACR, respectively (Becalski et al., 2003; De Meulenaer et al., 2008). Factors affecting ACR formation and degradation in foods are ACR precursors such as free amino acids (mainly asparagine), reducing sugars and processing conditions (i.e. baking time and temperature, moisture content and matrix of product) (Zhang et al., 2005). Very few studies have been conducted on short term toxicity, cardiotoxicity in animal models and apparently no study in human as well as in large animals. Along with this, amelioration of ACR toxicity has been studied in murine models with very low or non recovery from the patho-physiological alterations. After getting insights into the mode and mechanism of actions of ACR, the present was designed to evaluate the probable cardiotoxicity of ACR in Wistar rats and its amelioration using antioxidants like $\alpha$-tocopherol and reduced Glutathione (GSH).

\section{Materials and Methods}

\section{Experimental Animals}

Present study was designed to investigate the cardiotoxicity of acrylamide (ACR) and its amelioration using different antioxidants in
Wistar rats. The research work was conducted in Department of Veterinary microbiology and immunology, College of Veterinary Science and A.H., DUVASU, Mathura. Animals were maintained in standard cage system feeding having free access to pellet feed (Ashirwad Industries, Chandigarh) and clean, deionised drinking water was provided $a d$ lib to the animals during the entire study period. Daily light and dark cycle of $12 \mathrm{~h}$ was ensured so as to provide proper adaptation of biological clock to the experimental animals. Before start of the experiment, an acclimatization period of 15 days was allowed. All the experimental animals were kept under constant observation before and during the entire period of study to observe any morphological or physiological alterations. All experimental procedures were in accordance with the ethical principles in animal research and undertaken after approval of the institutional animal ethics committee (approval no. 119/IAEC/18 dated 23-022018).

\section{Experimental Design}

Thirty two adult male Wistar rats weighing between $130-150 \mathrm{~g}$ were divided into eight groups (G1-G8) during the study. The experimental groups were G1 (negative control, basal diet + water), G2 (basal diet $+\alpha$ tocopherol in corn oil), G3 (basal diet+ GSH in water), G4 (basal diet+ corn oil), G5 (basal diet +ACR), G6 (basal diet +ACR $+\alpha-$ tocopherol), G7 (basal diet +ACR + GSH), and G8 (basal diet $+\mathrm{ACR}+\mathrm{GSH}+\alpha$ tocopherol).

\section{Experimental Protocol}

Experimental animals were given uniform basal diet and adlib water. The acrylamide (Sigma, St Louis, USA) was dissolved in distilled water, and was given $30 \mathrm{mg} / \mathrm{KgBW}$ in groups G5-G8(15)before the basal diet by oral gavage using metallic needle (curved ball 
ended, size PS-16) every day in the morning for 45 days. The $\alpha$-tocopherol (Sigma, St Louis, USA) was dissolved in corn oil (vehicle for $\alpha$-tocopherol) and orally fed 100 $\mathrm{mg} / \mathrm{KgBW}$, and reduced Glutathione (GSH, Sigma, St Louis, USA) was dissolved in deionized water and fed, $2 \mathrm{mg} / \mathrm{KgBW}$ separately in G2 and G3 and in combined with ACR in G6-G8 (Sharma et al.,2020)

The dose of ACR was finalized from the results of the pilot study (data not shown) and the doses reported by other groups of researchers (Kahekeshani, 2014; Kumar et al., 2018, Sharma et al., 2020). The $\alpha$-tocopherol (Mandil et al., 2016, Sharma et al., 2020) and dose of GSH was selected from the reported literature (Gerard et al., 1992; Tredici et al., 1994 and Sharma et al., 2020).

\section{General Toxicity}

Rats of all the groups were closely observed during 45 days of experimental period for any apparent signs of toxicity including discomfort, gait, loss of hair, diarrhea, dermal problems, mortality, circling, non coordinating movements, poor reflex action, weight loss were observed and evaluated to study the toxicity levels.

\section{Organ weight}

At the starting and the end of the experiment the weight of the heart of individual rats were recorded and effect of different agents including the ameliorating agents were evaluated so as to access the effects of acrylamide on body weight.

\section{Oxidative stress biomarkers}

Frozen $\left(-20^{\circ} \mathrm{c}\right)$ samples of heart were thawed and $200 \mathrm{mg}$ of the each sample was taken and transferred to the test tube containing $2 \mathrm{ml}$ of chilled saline and $200 \mathrm{mg}$ each was taken in
$2 \mathrm{ml}$ of $0.02 \mathrm{M}$ EDTA for estimation of reduced glutathione (GSH) (Sedlak and Lindsay,1968), for lipid peroxidation (LPO) in terms of malondialdehyde (MDA) production (ShafiqU-Rehman,1984); catalase (Bergmeyer, 1983), superoxide dismutase (SOD) (Madesh and Balasubramanian, 1998), glutathione peroxidase (Paglia and Valantine et al., 1967), glutathione-S-transferase (Habig et al., 1974) and total protein content of tissue homogenate (Lowery et al., 1951).

\section{Histopathological Studies}

A small piece of heart of each rat from the respective groups (G1-8) collected and stored in $10 \%$ formal saline during postmortem examination were subject to histopathological evaluations using $\mathrm{H} \& \mathrm{E}$ stain as per the established method (Luna,1968) and examined to observe the changes in histoarchitecture of heart under 10x, 20x and 40x objective.

\section{Biochemical parameters}

Total cholesterol and total globulin in plasma samples were estimated by using the commercially available kits (Span Diagnostic Ltd.) with the help of UV-VIS spectrophotometer.

\section{Statistical analysis}

Statistical analysis was carried out by using the SPSS 16 package (Chicago, USA). Data from different experiments are presented as Mean \pm SEM. Means of the observations were compared by one way analysis of variance (ANOVA) to evaluate the variations and the significance was tested at 0.05 for all the observations.

To compare all pair-wise differences in mean Tukey post hoc test was used and means were considered statistically significant when $(\mathrm{P}<0.05)$. 


\section{Results and Discussion}

\section{Organ weight}

Absolute weights of the organ of rats revealed significant $(\mathrm{P}<0.05)$ reduction in weight ACR fed rats (G5) compared to control groups (G1$4)$; it is, however, the weights of heart of rats were significantly $(\mathrm{P}<0.05)$ higher in rats of G6 compared to G5 but lower in comparison to G7-8 (Table.1).

\section{Oxidative stress markers in Heart}

Activities of antioxidative enzymes GSH, SOD, GST and CAT significantly $(\mathrm{P}<0.05)$ lowered in G5 compared to all other groups (G1-4) in heart; and, the activities of these enzymes were higher in antioxidants co-fed with ACR groups (G6-G8) (Table 3). Interestingly, concurrent feeding of ACR along with $\alpha$-tocopherol significantly $(\mathrm{P}<0.05)$ increased the activities of SOD, GST and CAT compared to G7and G8 in heart.

\section{Assessment of Lipid peroxidation (in terms of MDA)}

The MDA levels in the heart were found significantly $(\mathrm{P}<0.05)$ higher in G5 compared to control groups (G1-G4) and other treatment groups (G6-G8). Rats of ACR co-fed with $\alpha-$ tocopherol, GSH and combination of both $\alpha$ tocopherol and GSH showed significant $(\mathrm{P}<$ 0.05) reduction in the MDA levels, but not higher to the groups without ACR (G1-G4). The lowest level of MDA was observed in G6 while highest was in G5 (Table 3).

\section{Histopathological changes}

The histopathological examination of liver in G1-G4 groups showed normal distribution of cardiac muscle fibres while on examine the heart of rats in G5 revealed severe degeneration, necrosis and separation of cardiac muscle fibers with extravassation of
RBCs. Interestingly, no improvement were observed in any other group of rats except G6. Histopathological examination revealed mild disruption of cardiac muscle fibers with very low extravassation of erythrocytes indicating ameliorative potential of $\alpha$-tocopherol (G6G8) (Figure.1).

\section{Assessment of Heart functions}

The serum levels of total protein, Globulin and cholesterol were significantly $(\mathrm{P}<0.05)$ increased in G5 compared to G1-G4 (Table 2). Rats co-fed with ACR and $\alpha$-tocopherol; ACR and GSH, showed marked $(\mathrm{P}<0.05)$ improvement in serum levels of total protein, Globulin and cholesterol. Interestingly, from the results it was evident that, serum cholesterol was affected by acrylamide feeding but none of the ameliorating agents was able to decrease the total protein in serum but concurrent feeding of $\alpha$-tocopherol with ACR (G6) has improved the cholesterol and globulin level in heart.

Present study was conducted in male Wistar rats for the study of acrylamide cardiotoxicity and its amelioration using different antioxidants ( $\alpha$-tocopherol and GSH).

The total study period was 45 days and was executed in eight experimental groups of rats. It is well established and known that ACR toxicity is mostly due to its intermediate metabolite glycidamide, which acts as a potential oxidant and induces oxidative stress in different organs. Therefore, the present is a attempt to understand the cardiotoxicity caused in the rats due to the oral administration of ACR and to assess the useful and beneficiary effect of concurrent feeding of antioxidant on the detrimental effects of ACR feeding in rats.

Previously, we reported that both $\alpha$-tocopherol and GSH provide protection from ACR induced neurotoxicity (Sharma et al., 2020) 
and our results suggested the better protection of $\alpha$-tocopherol against the ACR induced neurotoxicity in Wistar rats. In continuation of this study we now designed to understand the detrimental effects ACR feeding on heart (cardiotoxicity) and beneficial effect of antioxidants against the induced toxicity. We endorsed our findings with the assessment of histopathological changes, serum enzymes levels, anti-oxidative enzyme activities in heart and our findings reveals the better protection of $\alpha$-tocopherol and GSH against cardiotoxicity of oral administration of ACR to Wistar rats.

Table.1 Absolute weights of Heart in different groups of rats in the study (G1: Control; G2: Basal diet $+\alpha$-tocopherol; G3: Basal diet + GSH; G4: Basal diet + corn oil; G5: Basal diet + acrylamide; G6: Basal diet + acrylamide $+\alpha$-tocopherol; G7: Basal diet + acrylamide+ GSH; and G8: Basal diet $+\alpha$-tocopherol + GSH). Data are mean \pm Standard error of mean (SEM). Different superscripts in columns indicate differences $p<0.05$.

\begin{tabular}{|c|c|}
\hline \multicolumn{2}{|c|}{ Organ weight } \\
\hline \multicolumn{2}{|c|}{} \\
\hline Different Groups of Rats & Absolute weight of the Heart \\
\hline G1 & $0.96 \pm^{\mathrm{b}} 0.08$ \\
\hline G2 & $0.98 \pm^{\mathrm{b}} 0.06$ \\
\hline G3 & $0.96 \pm^{\mathrm{b}} 0.04$ \\
\hline G4 & $0.92 \pm^{\mathrm{b}} 0.08$ \\
\hline G5 & $0.68 \pm^{\mathrm{a}} 0.02$ \\
\hline G6 & $0.88 \pm^{\mathrm{b}} 0.02$ \\
\hline G7 & $0.80 \pm^{\mathrm{b}} 0.04$ \\
\hline G8 & $0.76 \pm^{\mathrm{b}} 0.04$ \\
\hline
\end{tabular}

Table.2 Serum chemistry (Total Cholesterol and Total Globulin) in different groups of rats during the study (G1: Control; G2: Basal diet $+\alpha$-tocopherol; G3: Basal diet + GSH; G4: Basal diet + corn oil; G5: Basal diet + acrylamide; G6: Basal diet + acrylamide $+\alpha$-tocopherol; G7: Basal diet + acrylamide + GSH; and G8: Basal diet $+\alpha$-tocopherol + GSH). Data are mean \pm Standard error of mean (SEM). Different superscripts in columns indicate differences $p<0.05$.

\begin{tabular}{|c|c|c|}
\hline & Biochemical Parameters & \\
\hline Different Groups of Rats & Total Cholesterol (mg/dl) & Total Globulin (g/dl) \\
\hline G1 & $40.10 \pm^{\mathrm{a}} 2.06$ & $3.10 \pm^{\mathrm{c}} 0.12$ \\
\hline G2 & $40.98 \pm^{\mathrm{a}} 2.05$ & $3.00 \pm^{\mathrm{c}} 0.12$ \\
\hline G3 & $40.68 \pm^{\mathrm{a}} 2.06$ & $3.00 \pm^{\mathrm{c}} 0.12$ \\
\hline G4 & $38.60 \pm^{\mathrm{a}} 2.68$ & $2.98 \pm^{\mathrm{b}} 0.18$ \\
\hline G5 & $46.80 \pm^{\mathrm{c}} 2.32$ & $2.60 \pm^{\mathrm{b}} 0.12$ \\
\hline G6 & $41.24 \pm^{\mathrm{b}} 2.12$ & $2.90 \pm^{\mathrm{b}} 0.12$ \\
\hline G7 & $45.12 \pm^{\mathrm{c}} 2.46$ & $2.60 \pm^{\mathrm{b}} 0.14$ \\
\hline G8 & $45.08 \pm^{\mathrm{c}} 2.78$ & $2.48 \pm^{\mathrm{a}} 0.12$ \\
\hline
\end{tabular}


Table.3 Oxidative stress markers in heart of different groups of rats fed with acrylamide and ameliorating agents. Data are presented as Mean \pm SEM. LPO (nM MDA/gm of tissue); SOD (U/mg of Protein); GSH (mM GSH/g of Tissue); GST ( $\mu$ M of CDNB-GSH conjugate/min/mg protein); CAT (mM H2O2 utilized/min/mg or protein). Different letters above the bar indicates significance $(p<0.05)$ among different groups in the columns. (G1: Control; G2: Basal diet $+\alpha-$ tocopherol; G3: Basal diet + GSH; G4: Basal diet + corn oil; G5: Basal diet + acrylamide; G6: Basal diet + acrylamide $+\alpha$-tocopherol; G7: Basal diet + acrylamide+ GSH; and G8: Basal diet $+\alpha$-tocopherol + GSH). Data are mean \pm Standard error of mean (SEM). Different superscripts in columns indicate differences $p<0.05$.

\begin{tabular}{|c|c|c|c|c|c|}
\hline \multicolumn{7}{|c|}{ Oxidative stress markers in Heart } & GST & CAT \\
\hline $\begin{array}{c}\text { Different Groups of } \\
\text { Rats }\end{array}$ & LPO & SOD & GSH & & \\
\hline G1 & $260.98 \pm^{\mathrm{a}} 4.78$ & $4.68 \pm^{\mathrm{a}} 0.14$ & $0.1 \pm^{\mathrm{a}} 0.06$ & $0.03 \pm \pm^{\mathrm{a}} 0.01$ & $3.90 \pm^{\mathrm{a}} 0.16$ \\
\hline G2 & $165.46 \pm^{\mathrm{b}} 4.32$ & $5.98 \pm^{\mathrm{b}} 0.68$ & $0.29 \pm^{\mathrm{b}} 0.02$ & $0.03 \pm \pm^{\mathrm{a}} 0.02$ & $4.64 \pm^{\mathrm{b}} 0.22$ \\
\hline G3 & $210.98 \pm^{\mathrm{c}} 4.78$ & $4.99 \pm^{\mathrm{a}} 0.46$ & $0.19 \pm^{\mathrm{a}} 0.06$ & $0.04 \pm^{\mathrm{b}} 0.01$ & $3.75 \pm \pm^{\mathrm{a}} 0.22$ \\
\hline G4 & $118.68 \pm^{\mathrm{a}} 3.68$ & $5.98 \pm^{\mathrm{b}} 1.30$ & $0.24 \pm^{\mathrm{b}} 0.04$ & $0.05 \pm^{\mathrm{c}} 0.02$ & $4.10 \pm \pm^{\mathrm{b}} 0.16$ \\
\hline G5 & $224.36 \pm^{\mathrm{c}} 2.86$ & $4.56 \pm^{\mathrm{a}} 0.38$ & $0.23 \pm^{\mathrm{a}} 0.04$ & $0.04 \pm^{\mathrm{b}} 0.02$ & $3.54 \pm^{\mathrm{a}} 0.10$ \\
\hline G6 & $125.68 \pm^{\mathrm{a}} 2.18$ & $6.28 \pm^{\mathrm{b}} 0.88$ & $0.29 \pm^{\mathrm{b}} 0.06$ & $0.06 \pm^{\mathrm{c}} 0.01$ & $4.38 \pm^{\mathrm{b}} 0.14$ \\
\hline G7 & $116.762 \pm^{\mathrm{a}} 2.86$ & $6.01 \pm^{\mathrm{b}} 0.36$ & $0.28 \pm^{\mathrm{b}} 0.04$ & $0.05 \pm^{\mathrm{c}} 0.02$ & $4.31 \pm^{\mathrm{b}} 0.24$ \\
\hline G8 & $118.64 \pm^{\mathrm{a}} 3.10$ & $6.08 \pm^{\mathrm{b}} 0.66$ & $0.26 \pm^{\mathrm{b}} 0.02$ & $0.06 \pm^{\mathrm{c}} 0.01$ & $4.34 \pm^{\mathrm{b}} 0.20$ \\
\hline
\end{tabular}

Fig.1

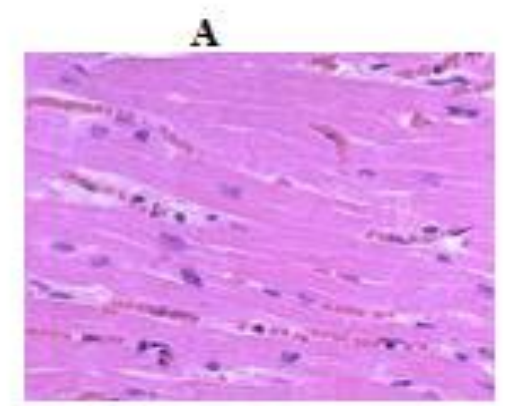

C

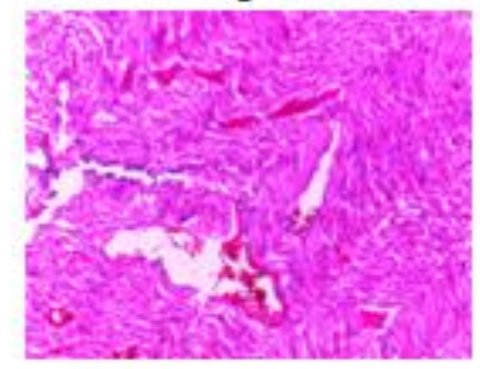

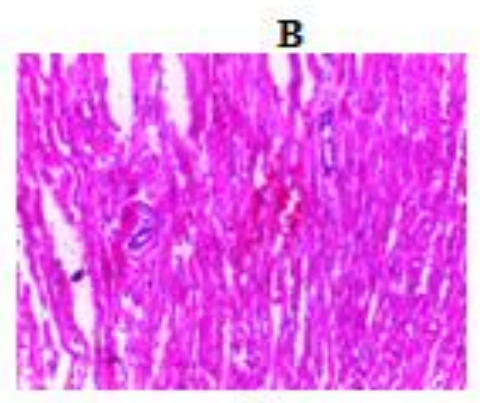

D

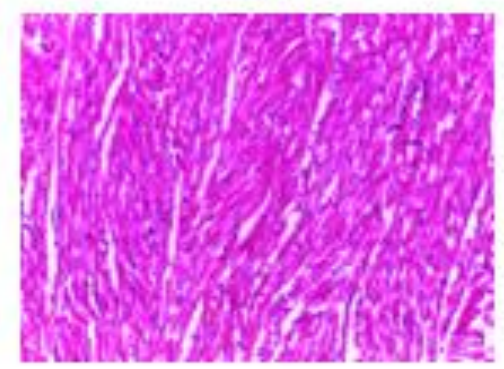

FIGURE A:GROUP 6-8 Heart showing normal distribution of cardiac muscle FIGURE B and C: GROUP 5 Heart of rats fed with ACR showing severe degeneration, necrosis and separation of cardiac muscle fibers with extravasations of RBCs. FIGURE D:GROUP 6 showing mild disruption of cardiac muscle fibers with mild extravasations of RBCs. 
Feeding with antioxidants $\alpha$-tocopherol and GSH resulted in significant improvement in antioxidative enzymes indicating the potential role of these agents in neutralising the effects of free radicals produced due to ACR. $\alpha$ tocopherol co-fed with ACR resulted in highest amelioration as compared to GSH. (Zhang, 2005c) There are two possibilities of this amelioration, either the antioxidants decreased the generation of ACR induced free radicals or they minimised the action of these free radicals by neutralising their toxic effects. Cardiac muscle cells are highly specialized cells and are non-regenerable like neurons. They are also targeted by free radicals and exhibit different degree of damage. ACR toxicity resulted in muscle cell degeneration indicating the potential role of ACR in inducing muscle cell damage through oxidative stress. Supplementation of $\alpha$ tocopherol resulted in marked improvement of muscle cells in heart but findings were not significant. It cannot be ruled out that, $\alpha$ tocopherol conferred cardiac protection but as cardiomyocytes are not regenerable, significant amelioration was not observed in cardiomyocytes during the study.

No studies are cited in literature regarding the protective potential of $\alpha$-tocopherol and GSH in ameliorating the ACR toxicity. However, numbers of studies have shown the potential roles of antioxidants in reducing the toxic effects of ACR in different organs.

The present study demonstrated that acrylamide toxicity induces Cardiac degeneration and severe toxicity in the heart, in supplementation with antioxidants like $\alpha$ tocopherol and GSH showed a differential level of amelioration in protecting the degeneration and tissue damage in heart. Coadministration of $\alpha$-tocopherol was found to be the very effective in ameliorating the acrylamide cardiotoxicity by reducing the oxidative damage in terms of decreasing the antioxidant mechanism and improving antioxidants system in the cells.

\section{Acknowledgement}

The authors are thankful to the Dean College Of Biotechnology, And Honorable Vice Chancellor of the University for providing all the necessary facilities.

\section{References}

Ashoor, S. H. and Zent, J. B. (1984). Maillard browning of common amino acids and sugars. J. Food. Sci. 49: 1206-1207.

Becalski, A., Lau, B. P. Y, Lewis, D. and Seaman, S. W. (2003). Acrylamide in foods: occurrence, sources, and modeling. J. Agric. Food. Chem. 51: 802-808.

Bergmeyer, H U. U. V. method of catalase assay. In: Methods of enzymatic analysis. Vol. III 3rd ed.Weinheim, Dacrfield Beach, Florida, Basal. (1983) 2;73

Carere, A. (2006). Genotoxicity and carcinogenicity of acrylamide: a critical review. Ann. Ist. Super. Sanita. 42: 144-155.

De Meulenaer, B, DeWilde, T. Mestdagh, F. Govaert, Y. and Ooghe, W. (2008). Comparison of potato varieties between seasons and their potential for acrylamide formation. J. Sci. Food. Agric. 88: 313-318.

Eriksson, S. (2005). Acrylamide in food products: Identification, formation and analytical methodology. Doctoral thesis, Department of Environmental Chemistry, Stockholm University, Sweden.

Gerard-Monnier D, Fougeat S, and Chaudiere J. Glutathione and cysteine depletion in rats and mice following acute intoxication with diethylmalonate. Biochem. Pharmacol. (1992) 43: 451- 
456.

Habig W, Pabst H, and Jakoby W B. Glutathione Stransferases. The first enzymatic step in mercapturic acid formation. J. Biol. Chem. (1974) 249: 7130-7139.

Kahkeshani N, Saeidnia S and Abdollahi M. Role of antioxidants and phytochemicals on acrylamide mitigation from food and reducing its toxicity. $J$. Food Sci. Tech. (2014) 52: 3169-3186.

Keramat, J. Lebail, A. Prost, C. and Jafari, M. (2011). Acrylamide in baking products: a review article. Food. Biopro. Tech. 4: 530-543.

Kumar J, Das S, and Teoh Lin S. Dietary Acrylamide and the Risks of Developing Cancer: Facts to Ponder. Front. Nutr. (2018) 5:14.

Lowry O H, Rosebrough $\mathrm{N}$ J, Farr A L. Protein measurement with the Folin phenol reagent. J. Biol. Chem. (1951) 193: 265-275.

Luna L G (1968) Manual of histology staining methods of the Armed Forces Institute of Pathology, $\quad 3^{\text {rd }}$ Edn.Mcgraw-Hill Book Co, New-York.

Madesh $M$ and Balasubramanian A $K$. Microtiter plate assay for superoxide dismutase using MTT reduction by superoxide. Indian J. Biochem. Biophy. (1998) 35:184-188.

Mandil R, Rahl A, Prakash A,Garg S K,Swain D K. Ameliorative potential of atocopherol against flubendiamide and copper-induced testicular-insult in Wistar rats. Chem-Biol. Interact.
(2016) 260: 91-101.

Paglia D E and Valentine W N. Studies on the quantitative and qualitative characterization of erythrocyte glutathione peroxidase. J. Lab. Clin. Med. (1967) 70(1):158-69.

Sedlak $\mathbf{J}$ and Lindsay R H. Estimation of total, protein-bound and non-protein sulfhydryl groups in tissue with Ellman's reagent. Anal. Bio. (1968) 25: 192-205.

Shafiq-U-Rehman. Lead-induced regional lipid peroxidation in brain. Toxicol. Lett. (1984) 21: 333-337.

Sharma P, Yadav S K, Kumar A, Singh V K, Singh R, Swain D K. Amelioration of acrylamide induced neurotoxicity in Wistar rats. J. Anim. Res. (2020) 10(2): 237-246.

Tredici G, Cavaletti G, Petruccioli M G. Lowdose glutathione administration in the prevention of cisplatin-induced peripheral neuropathy in rats. Neurotoxicology (1994) 15: 701-704.

Zhang, Y.; Zhang, G. Y. and Zhang, Y. (2005a). Occurrence and analytical methods of acrylamide in heat-treated foods: review and recent developments. J. Chromatogr. 1075:121.

Zhang, Y.; Zhang, Y.; Wu, X. Q. and You, X. (2005c). An applied method of extracts of bamboo leaves for reducing the formation of acrylamide in heat processing foods. Chinese Patent, $\mathrm{CN}$ 1663477A.

\section{How to cite this article:}

Pratishtha Sharma, Sharad K. Yadav, Amit Kumar, Vinod K. Singh, Renu Singh, Vikas Pathak and Dilip Kumar Swain. 2021. Detrimental Effects of Acrylamide Induced Cardiotoxicity and its Amelioration in Adult Male Wistar Rats. Int.J.Curr.Microbiol.App.Sci. 10(08): 34-41. doi: https://doi.org/10.20546/ijcmas.2021.1008.005 